\title{
Forming of Composite Cutting Layer on Tool Steel by Heat Treatment of CVD Coatings
}

\author{
Irina Belashova ${ }^{1}$, Larisa Petrova ${ }^{1}$, Peter Demin $^{1, a^{*}}$ and Mikhail Prokofyev ${ }^{2}$ \\ ${ }^{1}$ MADI University, Technology of structural materials department, 125319 Leningradskiy \\ prospect 64 Moscow, Russia \\ ${ }^{2}$ Moscow Aviation Institute (National Research University) 125993, Volokolamskoe shosse, 4 \\ Moscow, Russia \\ apetr-demin@yandex.ru
}

\section{Keywords: CVD, Coatings, Composite Layer, Heat Treatment, Chromium Carbides}

\begin{abstract}
CVD chromium coatings are evaporated on steel substrate from chrome-organic compounds. For crystallization with forming of nano-particles of chromium carbides, subsequent heating (annealing) of tool steel with hybrid coatings is carrying out. Significant increase of microhardness of the coating up to $27000 \mathrm{MPa}$ is observed due to the dispersion strengthening. Optimal annealing parameters (temperature and duration) are determined, which maximally strengthen the coatings and increase their adhesion to the steel substrate.
\end{abstract}

\section{Introduction}

Different techniques of surface strengthening are actively used for increase of service life of cutting tools. Among these techniques, the methods of coatings deposition are of special interest [1-3]. CVD method (Chemical Vapour Deposition) consists in condensation of a metal at a substrate after its reduction from decomposed chemical compound [4-5]. The technique of vapor deposition of chromium coatings from socalled MOC (metal-organic compounds) is an effective method for tool steels strengthening [3,5]. CVD chromium coatings have high physics-mechanical properties; however, the problem of peeling exists for coatings receiving without noticeable diffusion penetration of deposited element [6]. Precipitation of new phases may cause unfavorable stresses in the surface layer, which also lead to decrease in adhesion.

For coatings structure modification, subsequent heat treatment is used after the deposition [78]. The effect of additional heating of a coating on increase its adhesion to the steel substrate appears due to the forming of transition diffusion zone under the coating [9]. Heat treatment of amorphous chromium coatings gives the opportunity of carrying out controlled crystallization with precipitation of nano-dispersed chromium carbides and forming of strengthened composite layer [10]. In this paper, the influence of thermal effects of annealing on structure and properties of CVD chromium coatings on a tool steel is studied. The purpose of the study consists in definition of optimal deposition mode and subsequent annealing regimes for forming the structure for better adhesion and high strengthening level.

\section{Methods of experimental study}

CVD chromium coatings were received on substrates of low-alloyed tool steel grade T31507 by vapor deposition from chrome-organic compounds. In the reactor, condensation of chromium on a steel substrate occurs with forming of coatings with the thickness depending on the deposition time. The main parameters influencing on structure and properties of the coatings are: temperature of deposition, partial pressure in the reactor, velocity of vapors delivery to the reactor, and duration of the process. Samples of steel with chromium coatings were annealed directly in the reactor in vacuum with addition of argon at temperatures $510 \ldots 560^{\circ} \mathrm{C}$ during the time up to $180 \mathrm{~min}$. 
Microstructure of coatings was investigated by standard methods of metallographic analysis and scanned electronic microscopy. Strengthening of coatings was evaluated by measuring of their microhardness with loading of 50 grams.

Residual stresses parameters of samples with coatings $\left(-\sigma^{\phi}\right)$ were determined by measuring of their deflection. Adhesion strength of chromium coatings to the steel substrate was assessed during tensile tests with measuring the relative adhesion index RAI $=\left(\mathrm{m}_{\mathrm{C}} / \mathrm{m}_{0}\right) \cdot 100 \%$, where $\mathrm{m}_{\mathrm{C}}$ is the mass of the specimen after compression tests; and $m_{0}$ is the initial mass of the specimen before tests.

\section{Results and discussion}

The lowest temperature of deposition $\left(420 \ldots 430^{\circ} \mathrm{C}\right)$ is limited by the intensity of evaporation process. At these temperatures, the kinetic mode of deposition is realized; and the coatings are fully amorphous. At high temperatures $\left(510 \ldots 520^{\circ} \mathrm{C}\right)$, the diffusion mode of deposition provides intensive mass transfer of initial chemical compound to the surface of a substrate forming fully crystallized coating morphology. At intermediate temperatures $\left(450 \ldots 480^{\circ} \mathrm{C}\right)$, growth of the coatings occurs according to the hybrid diffusion-kinetic mode. Hybrid coating have layered structure (Fig. 1 a) consisting of alternating amorphous and crystalline interlayers that is the consequence of cyclic delivery of MOC.
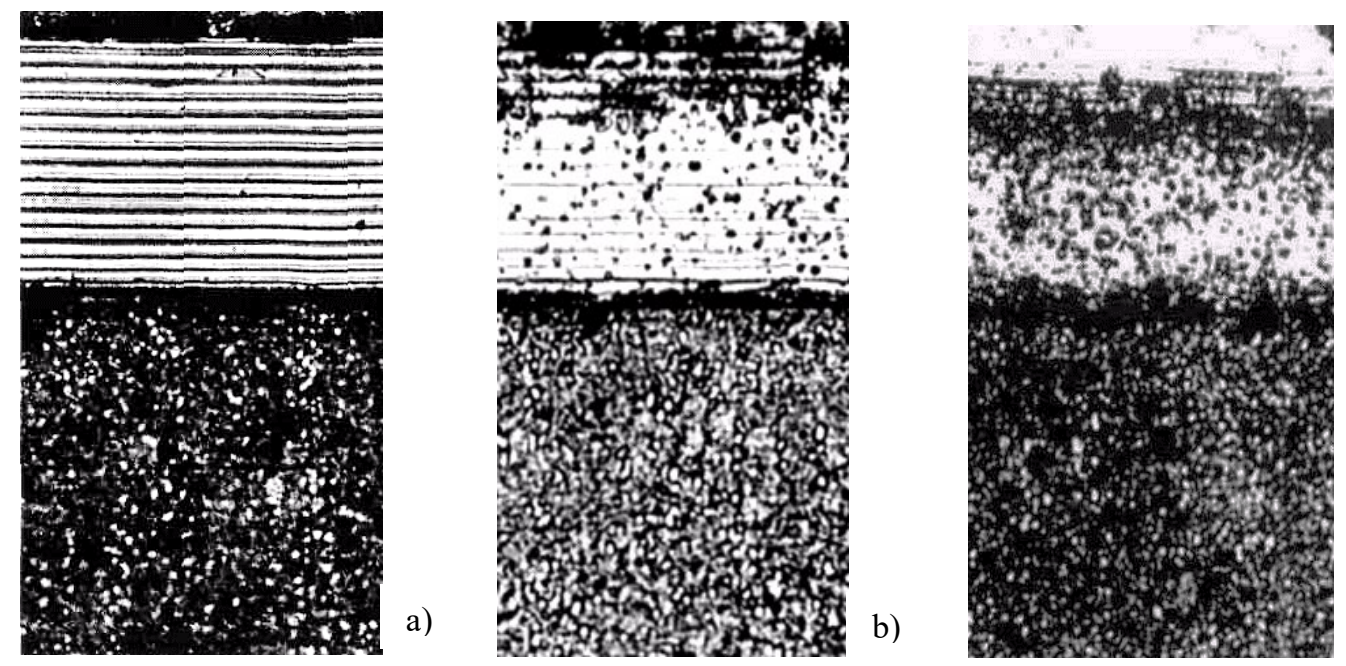

c)

Fig. 1. Microstructures of chromium coatings on tool steel deposited at $470^{\circ} \mathrm{C}$ (time of deposition is $15 \mathrm{~min}$ ), x500: a)-as-received; b)-annealed at $550^{\circ} \mathrm{C} 0.5 \mathrm{~h}$; c)-annealed at $550^{\circ} \mathrm{C} 1.5 \mathrm{~h}$

The total thickness of hybrid coatings after $15 \mathrm{~min}$ of deposition is about 6 microns. The light layers are amorphous solid solution of carbon in chromium, whereas the dark layers have crystal structure composed of chromium and its carbides $\mathrm{Cr}_{7} \mathrm{C}_{3}, \mathrm{Cr}_{23} \mathrm{C}_{6}$. Changes of MOC concentration near the substrate leads to redistribution of carbon between the layers: crystal phase contains more carbon than the amorphous one.

The mode of deposition affects the residual stresses in the coating and, consequently, influence on its adhesion. The minimum stress level corresponds to the kinetic mode of deposition and formation of amorphous coatings (Fig. 2). With transition to the hybrid deposition mode an increase in stresses is observed. This effect is associated with the appearance of crystalline carbides interlayers in the amorphous phase, which is accompanied by an increase in volume. In the coatings received in the diffusion mode of deposition $\left(510^{\circ} \mathrm{C}\right)$, the stresses reach their maximum. 
As the diffusion deposition temperature increases, carbide inclusions become larger, which leads to a decrease in internal stresses.

The level of residual stresses depends not only on the deposition temperature, but also on the coating thickness, which is determined by the time of deposition: the value of residual stresses is higher with increasing coating thickness (Fig. 2).

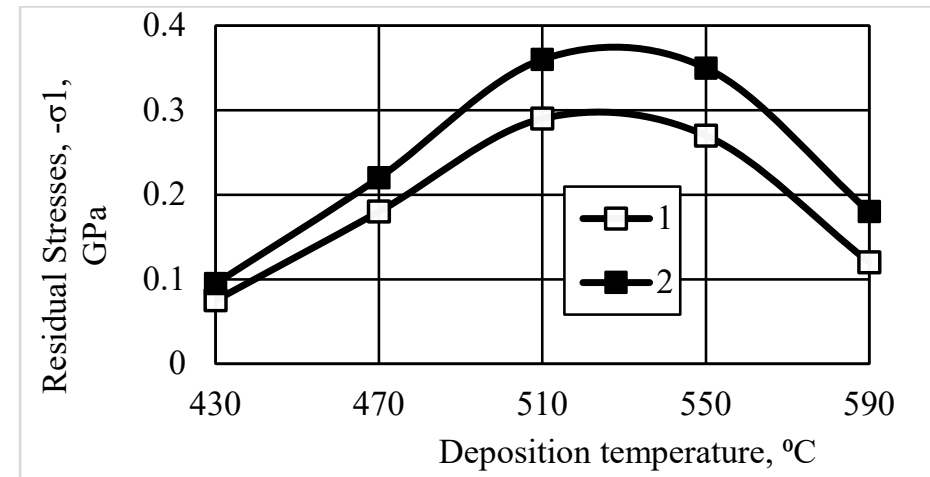

Fig. 2. Residual stresses in chromium coatings with the thickness of $3 \mu \mathrm{m}$ (1) and $6 \mu \mathrm{m}$ (2) deposited at different temperatures.

Annealing of coatings deposited in the kinetic and in the diffusion modes does not results in noticeable modification of their structure. Amorphous coatings formed in the kinetic mode of deposition have no conditions for nucleation of a crystal phase. Coatings received in the diffusion mode of deposition are sustainable to heating due to the fully formed crystal structure.

Heat treatment of hybrid coatings allows implementing the crystallization of amorphous layers. Dispersed precipitations of chromium carbides in crystal interlayers may serve as the nucleuses for crystallization process. As far as the amorphous phase is unstable, the system drives to the equilibrium by forming crystal structure based on chromium carbides.

Annealing at temperatures below $500^{\circ} \mathrm{C}$ does not result in any changes of coatings' structure. At temperatures higher than $600^{\circ} \mathrm{C}$, the initial layered structure of the coating disappears; and they receive crystal-grained structure.

For precipitation of crystal nucleuses in amorphous phase, the annealing at intermediate temperatures $540-560^{\circ} \mathrm{C}$ should be used. After soaking at these temperatures, precipitations of carbide particles are observed in hybrid coatings (Fig. $1 \mathrm{~b}$ ). Increase of the annealing time leads to further activation of crystallization process; as a result, crystal structure is spread progressively to the whole coating, and amorphous phase disappears (Fig. $1 \mathrm{c}$ ). A transitional zone is formed under the coating with the thickness up to 20 microns that makes micrihardness profiles smoother (Fig. 3).

Strengthening achieving in chromium coatings just after deposition depends on the deposition mode (deposition temperature). Microhardness of amorphous coatings received in the kinetic mode of deposition is up to $14000 \mathrm{MPa}$. Maximal microharness (up to $19500 \mathrm{MPa}$ ) is achieved after deposition at temperatures of initial diffusion regime $\left(500 \ldots 510^{\circ} \mathrm{C}\right)$ when fine-grained structure of coatings is formed. Chromium coatings of hybrid deposition mode $\left(450 \ldots 480^{\circ} \mathrm{C}\right)$ have microhardness value about $16000 \mathrm{MPa}$.

Annealing of hybrid coatings may increase their microhardness additionally (Fig. 3). Strengthening of heat-treated coatings depends on the temperature of annealing (Fig. 4 a). Annealing at the temperatures below $500 \mathrm{oC}$ does not make changes of microhardness. Increase of the temperature enough for starting the crystallization $\left(540 \ldots 550^{\circ} \mathrm{C}\right)$ results in the explosive growth of microhardness up to $22000 \ldots 27000 \mathrm{MPa}$. This is the effect of dispersion hardening by nanoparticles of chromium carbides coherent with solid solution. Increase of the annealing temperature leads to slight decrease of microhardness due to the coagulation of chromium carbides. 


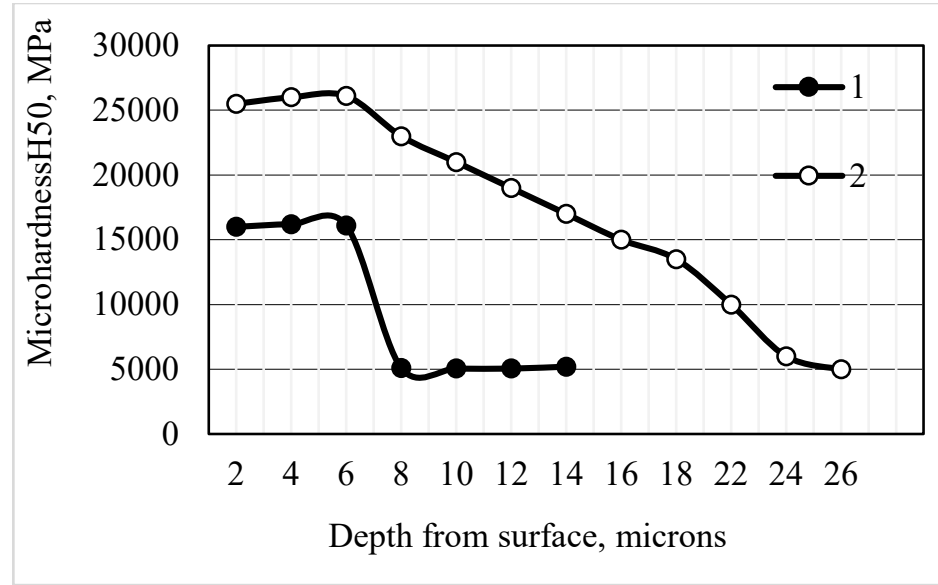

Fig. 3. Microhardness profiles of coatings on tool steel after deposition in hybrid mode (1), and after subsequent annealing at $550^{\circ} \mathrm{C}, 1$ hour (2)

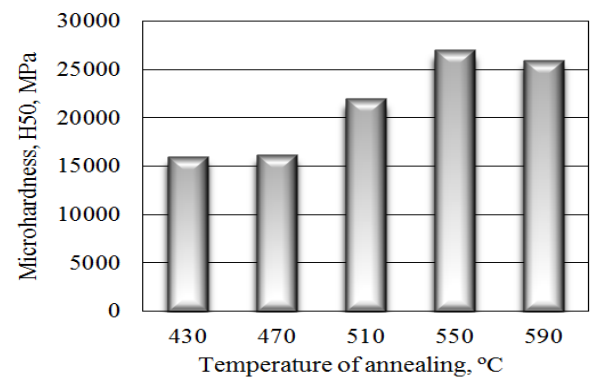

a

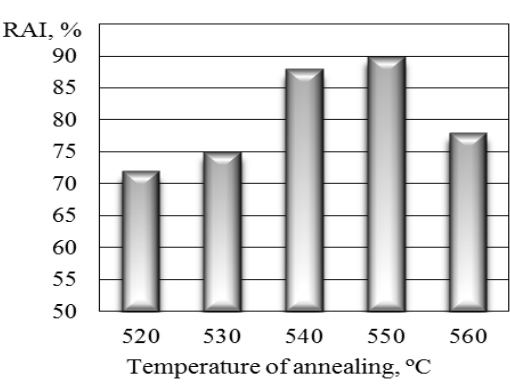

$\mathrm{b}$

Fig. 4. Influence of annealing temperature on microhardness of CVD coatings (a) and on their adhesion (b)

Adhesion resistance of coatings depends on the degree of crystallization: crystallized carbides appearing during the annealing increases the level of internal stresses. Completion of crystallization at higher temperatures decreases distortions and weakens cohesive interaction in the coating. The level of adhesion resistance slightly decrease (by 7-10\%) at combined crystallizing treatment (Fig. 4 b).

\section{Conclusion}

The formation of strengthened composite chromium-carbide layers on the surface of tool steel has been experimentally confirmed by annealing of chromium CVD coatings deposited in a hybrid (kineticdiffusion) temperature mode. The microstructure of the composite coatings is a result of crystallization of amorphous interlayers and formation of nano-particles of chromium carbides. This increases the microhardness of the coating due to dispersion strengthening.

Heating the coating at annealing temperatures of $540 \ldots 560^{\circ} \mathrm{C}$ activates diffusion processes. A transition layer is formed between the coatings and the substrate, which increases their adhesion. This correlates with the increase of the compressive residual stresses after the crystallization and precipitation of coherent carbides.

There are optimal annealing parameters (temperature and duration), which maximally strengthen the coatings and increase their adhesion to the steel substrate. The lower limits of these parameters are associated with the crystallization initiation, and the upper limits are determined by the coagulation of carbide particles, which causes stress relaxation. 


\section{Acknowledgments}

The material was prepared within the framework of scientific research under the project №FSFM2020-0011 (2019-1342); experimental studies were carried out using the equipment of the MADI Centre of collective usage.

\section{References}

[1] M. Diesselberg, H.R. Stock, P. Mayr Friction and wear behaviour of PVD chromium nitride supported carbon coatings/ Surface and Coatings Technology. 2004. T. 188-189. № 1-3 SPEC.ISS. C. pp. 612-616. https://doi.org/10.1016/j.surfcoat.2004.07.023

[2] L.S. Kremnev, A.K. Onegina, L.A. Vinogradova, I.Yu Sapronov. Special features of the composition, structure and properties of high-speed steels for cutting tools with ion-plasma coatings based on titanium nitride, Metal Science and Heat Treatment, 2012. T. 54. № 1-2. pp. 37. https://doi.org/10.1007/s11041-012-9446-y

[3] V.I. Yurshev, R.I. Mukatdarov, I.V. Yurshev Surface hardening of tools by depositing a pyrolytic chromium carbide coating, Metal Science and Heat Treatment. 2015. T. 57. № 1. pp. 107-111. https://doi.org/10.1007/s11041-015-9845-y

[4] T.A. Tabaza, O.T. Tabaza, A. Al-Sakarneh CVD technology for preparing chromium oxide coatings, study of the kinetics of growth of coatings, Key Engineering Materials. 2018. T. 765 KEM. C. pp.193-198. https://doi.org/10.4028/www.scientific.net/KEM.765.193

[5] L.L. Ivanov Development of strengthening technology for cutting tools by deposition of pyrolitic chromium coatings, PhD Theses, Moscow, MADI, 1988. 242

[6] A. Vereschaka, A. Aksenenko, S. Shevchenko, et al. Effect of adhesion and tribological properties of modified composite nano-structured multi-layer nitride coatings on WC-Co tools life/Tribology International. 2018. T. 128. pp. 313-327. https://doi.org/10.1016/j.triboint.2018.07.039

[7] X. Pang, K. Gao, F. Luo, H. Yang, L. Qiao, Y. Wang, A.A. Volinsky Annealing effects on microstructure and mechanical properties of chromium oxide coatings, Thin Solid Films. 2008. T. 516. № 15. C. pp. 4685-4689. https://doi.org/10.1016/j.tsf.2007.08.083

[8] O.V. Somov, V.A. Pashkin, S.V. Savushkina, B.L. Krit Pyrolytic chromium carbide coatings on steel: effect of annealing on morphology and elemental composition,Surface Engineering and Applied Electrochemistry. 2020. T. 56. № 2. C. pp.140-146. https://doi.org/10.3103/S1068375520020179

[9] L.G. Petrova, P.E. Demin, G.Y. Timofeeva, A.V. Kosachev, V.D. Aleksandrov Influence of nitriding on the wear resistance and adhesion of zinc coatings on steel, Russian Engineering Research. 2019. T. 39. № 8. C. pp.696-698. https://doi.org/10.3103/S1068798X1908015X

[10] I.S. Belashova, L.G. Petrova Dispersion Hardening of Amorphous Chromium Coatings by Crystallized Nano-Particles of Carbides, European Conference of Heat Treatment and 21st IFHTSE Congress, May 2014, Munich, Germany, pp..505-510 